\title{
Efficacy and Safety of Direct Factor Xa Inhibitors Versus Warfarin in Prevention of Primary and Secondary Ischemic Strokes in Non-Valvular Atrial Fibrillation: A Literature Review
}

\author{
Mina Emamy ${ }^{1}$, Tehrim Zahid ${ }^{1}$, Robert Ryad ${ }^{1}$, Suhail M. Saad-Omer ${ }^{2}$, Nusrat Jahan ${ }^{1}$ \\ 1. Internal Medicine, California Institute of Behavioral Neurosciences \& Psychology, Fairfield, USA 2. Medicine, \\ California Institute of Behavioral Neurosciences \& Psychology, Fairfield, USA
}

Corresponding author: Mina Emamy, mina.emamy.298@gmail.com

\begin{abstract}
Ischemic stroke remains a major cause of mortality and morbidity in patients with atrial fibrillation. The use of appropriate anticoagulants reduces the risk of ischemic stroke in these patients. The current literature review is aimed to analyze the follow-up efficacy and safety of direct factor Xa inhibitors versus warfarin in the prevention of primary and secondary ischemic stroke, risk of major and minor bleedings, and food and drug interaction in patients with atrial fibrillation (AF). We selected PubMed as our database and we found 83,611 articles using the regular keyword 'atrial fibrillation'. We found 2,224 articles using the regular keywords 'direct factor Xa inhibitors' and 'atrial fibrillation'.
\end{abstract}

Finally, we obtained 326 studies using MeSH keywords: atrial fibrillation, direct factor Xa inhibitors, and warfarin. Ultimately, 46 articles were selected after applying the inclusion/exclusion criteria. All studies were randomized controlled trials (RCT) or clinical trials. Analysis of all studies showed that direct factor Xa inhibitors are superior to warfarin in the prevention of ischemic stroke in patients with non-valvular AF, with a lower rate of major and minor bleeding events and lower foods and drug interaction. Unlike warfarin, direct factor Xa inhibitors do not need frequent blood monitoring and dose adjustment. We found that warfarin and other vitamin $\mathrm{K}$ inhibitors may promote the calcification of heart valves and coronary arteries. There is some evidence that direct factor Xa inhibitors may slightly reverse these calcifications in coronary arteries and heart valves.

Categories: Cardiology, Internal Medicine, Neurology

Keywords: atrial fibrillation, direct factor xa inhibitors, warfarin

\section{Introduction And Background}

Received 07/11/2020 Review began 07/14/2020 Review ended 07/25/2020 Published 07/26/2020

() Copyright 2020 Emamy et al. This is an open access article distributed under the terms of the Creative Commons Attribution License CC-BY 4.0., which permits unrestricted use, distribution, and reproduction in any medium, provided the original author and source are credited.
The number of patients with atrial fibrillation (AF) who need stroke prevention continues to rise. The prevalence of AF increases with age and is associated with a higher risk of ischemic stroke. The use of warfarin reduces the risk of ischemic stroke in patients with $\mathrm{AF}$, but they need frequent monitoring and dose adjustment [1]. Ischemic stroke is considered as a focal neurological deficit from non-traumatic and nonhemorrhagic causes. AF is the cause of ischemic stroke in $15 \%$ of all ages and $30 \%$ of people over 80 years of age. The risk of ischemic stroke increases significantly with anticoagulant cessation [2].

The importance of a safe and effective prevention guideline with the best antiplatelets and anticoagulants combination is a major goal for medicine. Oral direct factor Xa inhibitors (xabans) are approved by the United States Food and Drug Administration (FDA) for the prevention of stroke. Warfarin is an antagonist of vitamin K. Xabans have a different effect in the clotting cascade. They act directly upon factor Xa. They have fewer drug and food interactions, and their location in the coagulation cascade promises their efficiency. There is no need to monitor their effects by checking the international normalized ratio (INR). This current review shows that xabans are at least as safe as warfarin in the elderly, patients with impaired liver and renal function, and in patients with a CHA2DS2-VASc score 2 or greater (scores that use factors like age, sex, history of stroke, hypertension and diabetes to estimate the risk of ischemic stroke in AF. A score of 2 or greater is moderate to high risk). Most physicians prefer these drugs over warfarin; however, there might be some limitations like patients' kidney and liver function and the fact that they are not yet approved for valvular AF. Physicians need to consider the risk of bleeding, and the patient's drug combination like their interaction with antiplatelet medications (like aspirin and clopidogrel).

There are some clinical benefits of xabans over warfarin. Based on current data, the best combination for the prevention of primary and secondary ischemic stroke in patients with AF would be aspirin plus clopidogrel and one xaban, such as apixaban, edoxaban, rivaroxaban, and darexaban [3]. There are still some challenging questions regarding the potential benefits of xabans over warfarin: How is their efficacy in the prevention of primary and secondary strokes compared to warfarin? How are their safety (minor and major bleedings) and food and drug interaction compared to warfarin? 


\section{Cureus}

The presented literature review focused on the efficacy and safety of using xabans versus warfarin in the prevention of primary and secondary ischemic strokes in patients with non-valvular AF. This information will help clinicians to improve the outcomes of patients with AF.

\section{Review}

\section{Method and results}

Data were collected manually on PubMed using parallel strategies derived from MeSH keywords and regular keywords. Table 1 represents all keywords used for this review.

\section{Regular and MeSH keywords}

Regular keyword: atrial fibrillation

Total articles

Articles selected

Regular keyword: direct factor Xa inhibitors

Total articles

Articles selected

MeSH keywords: atrial fibrillation, direct factor Xa inhibitors, warfarin

Total articles

Articles selected

TABLE 1: Data regarding the number of articles obtained using regular and MeSH keywords.

This review has been generated after including the following inclusion/exclusion criteria. Table 2 represents the inclusion/exclusion criteria.

\section{Inclusion criteria}

Studies in the English language

Randomized controlled trials and clinical trials

Human studies

Studies in the last 10 years

Studies on patients with confirmed atrial fibrillation

Subjects of age above 18 years

\section{Exclusion criteria}

Studies other than randomized clinical trials and clinical trials

Animal studies

Studies that have been done more than 10 years ago

Subjects of age below 18 years

TABLE 2: The inclusion/exclusion criteria.

We found 83,611 articles using the regular keyword 'atrial fibrillation'. We noted 2,224 articles using the regular keywords: 'direct factor Xa inhibitors' and 'atrial fibrillation'. Finally, we obtained 326 studies using MeSH keywords: 'atrial fibrillation', 'direct factor Xa inhibitors', and 'warfarin'. Ultimately, 46 articles were selected regarding the exclusion/inclusion criteria. All 46 studies that were chosen at the end had full articles available. They were all randomized controlled trials (RCTs) or clinical trials on human subjects. All articles have been in the English language since 10 years ago.

\section{Study design}

All studies were clinical trials and RCTs. The maximum number of subjects among all reviewed articles was 21,105 and the minimum number of subjects was 45 [4,5]. Among all studies, 29 studies compared different xabans with warfarin. These alternative drugs included apixaban for six studies, rivaroxaban in fifteen studies, edoxaban for seven studies, and darexaban in one study [1-4,6-30]. Finally, six studies evaluated the 
effects of different types of non-vitamin K oral anticoagulants with warfarin [5,31-35]. This review shows that xabans are more efficient in the prevention of ischemic stroke in patients with non-valvular AF. There is less drug and food interaction when patients receive xabans. Also, the mortality rate, risk of major and minor bleedings, and hemorrhagic stroke are less common in patients who receive xabans compared to patients who receive warfarin.

Figure 1 represents the flowchart with the selection process for this literature review.

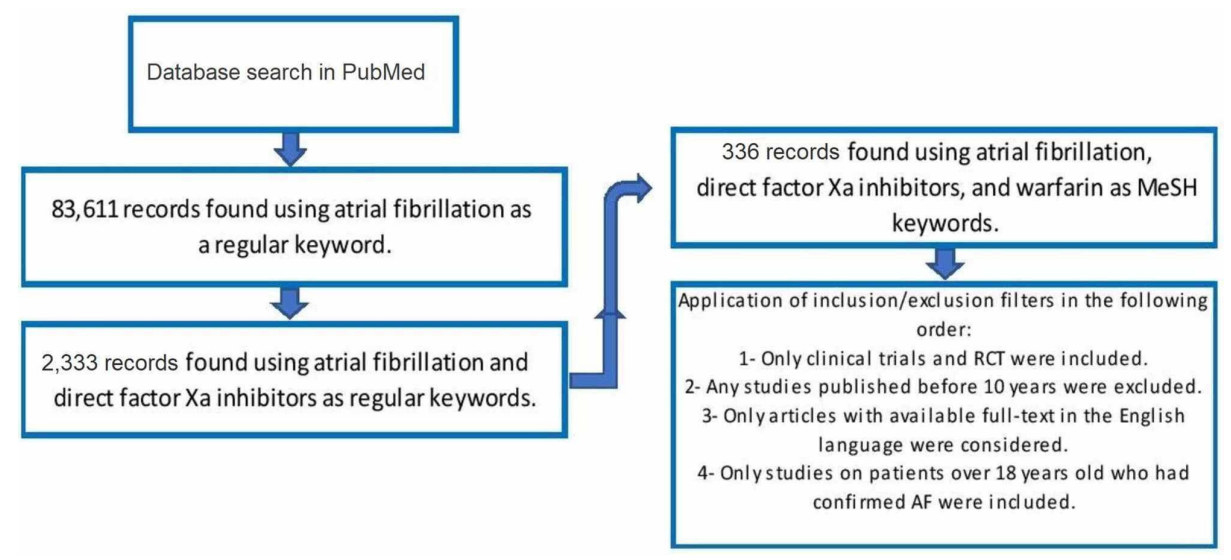

\section{FIGURE 1: The flowchart that represents the selection process of the current literature review.}

$\mathrm{AF}$, atrial fibrillation; $\mathrm{RCT}$, randomized controlled trial

\section{Discussion}

$\mathrm{AF}$ is correlated with a higher risk of ischemic stroke. A stroke resulting from AF is more likely to be disabling than a non-AF stroke [28]. The importance of a more beneficial anticoagulant resulted in many clinical trials to compare these treatments. This review was performed to demonstrate that xabans are superior to warfarin in the prevention of ischemic stroke in patients with non-valvular AF. Also, we think that xabans have a lower rate of major and minor bleeding events and lower foods and drug interaction. We found that the majority of RCTs supported our hypothesis. We also found that xabans are at least as safe as warfarin in the elderly, patients with renal failure, patients with impaired liver function, and in patients with a CHA2DS2-VASc score 2 or greater.

Major bleeding is explained by the International Society of Thrombosis and Haemostasis (ISTH) as a decline in the hemoglobin of at least two grams per deciliter, or if a patient needs at least two units of packed red blood cells, or if bleeding happens in critical sites, or bleeding that causes death. A non- major bleeding does not satisfy the criteria for major bleeding. Hematuria, epistaxis, gastrointestinal (GI) bleeding, and ecchymosis are the most frequent sites of non-major bleedings. A review of different studies demonstrated that the risk of minor and major bleedings for xabans is not more than warfarin [6]. Vitamin $\mathrm{K}$ antagonists like warfarin have a very narrow therapeutic index, many drug interactions, and also patients need to be monitored regularly [31]. There have been multiple studies that compared the outcome of patients with AF who are treated with xabans versus warfarin (Table 3).

In a RCT, 27 patients with cirrhosis received direct oral anticoagulants (DOAC) and 18 patients with cirrhosis received warfarin and low molecular weight heparin (LMWH). Only one patient in the DOAC group (4\%) had major bleeding compared with five patients in the warfarin and LMWH groups (28\%). The rate of thrombosis including ischemic stroke was $4 \%$ in the DOAC group vs. $6 \%$ in the warfarin and LMWH groups. These results support the preference of DOAC to warfarin and LMWH in patients with liver failure and cirrhosis [5]. Different clinical trials demonstrated that even in patients with a high-risk profile (elderly, patients with diabetes mellitus, cirrhosis, recurrent stroke, concomitant medications, and severe heart failure) still, xabans are superior to warfarin [27]. Vitamin K inhibitors inhibit post-translational activation of coagulation factors that are vitamin $\mathrm{K}$ dependents. On the other hand, they decrease the production of extrahepatic vitamin k-dependent proteins. This side effect promotes the calcification of heart valves and coronary arteries. Also, it has been shown that the consumption of vitamin $\mathrm{K}$ decreases the calcification of coronary arteries and heart valves [6].

Another randomized controlled study showed that apixaban not only has been superior to warfarin in the prevention of primary endpoints (ischemic stroke and other thromboembolic events), but it also prevents myocardial infarction (12\%) [1]. An RCT compared warfarin with rivaroxaban in patients who use several 
concomitant medications. The study included the cohort of 5,101 patients with AF who used 0-4 medications, 7,298 patients who took 5-9 concomitant medications, and 1,865 patients who received 10 or more other medications. The concomitant medications were acetylsalicylic acid (ASA), angiotensinconverting enzyme inhibitors, beta-blockers, digitals, and diuretics. The study found out that the risk of stroke or peripheral embolism was not higher in patients who received fewer than 10 concomitant medications, but the risk of major bleeding events and all other causes of death increased by the number of concomitant medications. The risk of major bleeding was 11.64 per 100 patient-years for patients who took 0-4 medications, 14.79 per 100 patient-years for patients who received 5-9 medications, and 23.42 per 100 patient-years for patients who received 10 or more than 10 concomitant medications. In this study, there was not any significant different outcome between rivaroxaban and warfarin across all three groups [21].

However, two of the selected studies for this review had some different results. In one clinical trial, there was a significantly higher chance of GI bleeding in patients who received rivaroxaban compared to patients who were treated with warfarin (3.61 vs. 2.60 per 100 patient-years) [15]. Also, in another clinical trial, the efficacy of rivaroxaban vs. warfarin in the prevention of stroke was 1.71 vs. 1.95 per 100 patient-years in older patients (>75 years) [10]. The current literature review has some limitations: the study limits its analysis of studies in the previous 10 years on patients who are at least 18 years old, and RCTs and clinical trials who had a full article available.

Table 3 summarizes some of the studies that compared the efficacy and safety of xabans with warfarin in patients with non-valvular AF.

\begin{tabular}{|c|c|c|c|c|c|}
\hline Author/Date & $\begin{array}{l}\text { Study } \\
\text { Design }\end{array}$ & $\begin{array}{l}\text { Subjects } \\
\text { Received } \\
\text { Xabans }\end{array}$ & $\begin{array}{l}\text { Subjects } \\
\text { Received } \\
\text { Warfarin }\end{array}$ & $\begin{array}{l}\text { Total } \\
\text { Number } \\
\text { of } \\
\text { Subjects }\end{array}$ & Main Points \\
\hline $\begin{array}{l}\text { Giugliano et } \\
\text { al. [4], } 2013\end{array}$ & $\begin{array}{l}\text { Randomized } \\
\text { controlled } \\
\text { trial }\end{array}$ & $\begin{array}{l}7,035 \\
\text { (high } \\
\text { dose) } \\
7,034 \\
\text { (low } \\
\text { dose) }\end{array}$ & 7,036 & 21,105 & $\begin{array}{l}\text { Subjects in the warfarin group had } 1.50 \% \text { of developing an ischemic } \\
\text { stroke or a systemic embolism ( } 232 \text { patients)., while only } 182 \\
\text { participants from the high-dose edoxaban group }(1.18 \%) \text { and } 253 \\
\text { participants from the low-dose edoxaban group }(1.61 \%) \text { developed } \\
\text { an ischemic stroke or an embolic event. }\end{array}$ \\
\hline $\begin{array}{l}\text { Granger et } \\
\text { al. [1], } 2011\end{array}$ & $\begin{array}{l}\text { Randomized } \\
\text { controlled } \\
\text { trial }\end{array}$ & 9,120 & 9,081 & 18,201 & $\begin{array}{l}\text { All subjects that had two or more episodes of AF are documented } \\
\text { by ECG and at least one risk factor for stroke. Apixaban decreased } \\
60 \% \text { in the risk of stroke or systemic embolism. Warfarin decreased } \\
50 \% \text { in the risk of stroke or systemic embolism. People who } \\
\text { received apixaban had an ischemic stroke in } 162 \text { patients }(0.97 \%) \text {, } \\
\text { hemorrhagic stroke in } 40 \text { patients }(0.24 \%) \text {, and major bleeding in } \\
327 \text { patients }(2.13 \%) \text {. On the other hand, people who received } \\
\text { warfarin had an ischemic stroke in } 175 \text { patients }(1.05 \% .) \text {, } \\
\text { hemorrhagic stroke in } 78 \text { patients }(0.47 \%) \text {, and major bleeding in } \\
462 \text { patients }(3.09 \%) \text {. }\end{array}$ \\
\hline $\begin{array}{l}\text { Banit et al, } \\
\text { [9], } 2017\end{array}$ & $\begin{array}{l}\text { Randomized } \\
\text { controlled } \\
\text { trial }\end{array}$ & 9,088 & 9,052 & 18,140 & $\begin{array}{l}\text { The study found that like major bleedings and non-major bleedings } \\
\text { were also more common in patients treated with warfarin vs. } \\
\text { apixaban ( } 9.4 \text { vs. } 6.4 \text { per } 100 \text { patient-years). }\end{array}$ \\
\hline $\begin{array}{l}\text { Patel et al. } \\
\text { [17], } 2011\end{array}$ & $\begin{array}{l}\text { Randomized } \\
\text { controlled } \\
\text { trial }\end{array}$ & 7,131 & 7,133 & 14,264 & $\begin{array}{l}\text { Participants were at moderate to severe risk for stroke (ejection } \\
\text { fraction less than } 35 \% \text {, high blood pressure, diabetes mellitus, or } \\
\text { age }>75 \text { years). For people who received rivaroxaban }(15-20 \mathrm{mg} \\
\text { daily), fatal bleeding and intracranial hemorrhage in } 82 \text { patients } \\
(0.7 \%) \text { vs. fatal bleeding and intracranial hemorrhage in } 139 \text { patients } \\
(1.2 \%) \text { in the warfarin group. }\end{array}$ \\
\hline $\begin{array}{l}\text { Goodman et } \\
\text { al. [20], } 2014\end{array}$ & $\begin{array}{l}\text { Randomized } \\
\text { controlled } \\
\text { trial }\end{array}$ & 7,111 & 7,125 & 14,236 & $\begin{array}{l}\text { Major bleeding events happened correspondingly in two groups } \\
(3.60 \text { per } 100 \text { patient-years for rivaroxaban users vs. } 3.45 \text { per } 100 \\
\text { patient-years for warfarin users). For both groups, the risk of } \\
\text { bleeding increased by age, smoking, anemia, history of previous } \\
\text { gastrointestinal bleeding, and prior usage of acetylsalicylic acid } \\
\text { (ASA). }\end{array}$ \\
\hline Bansila & $\begin{array}{l}\text { Randomized } \\
\text { controlled }\end{array}$ & 7,131 & (,133 & 14,264 & $\begin{array}{l}\text { In this study, 2,878 patients with diabetes and AF received } \\
\text { rivaroxaban and 2,817 patients with diabetes and AF received } \\
\text { warfarin. Also, 4,253 non-diabetic patients received rivaroxaban and } \\
4,316 \text { non-diabetic participants with AF received warfarin. Diabetic }\end{array}$ \\
\hline
\end{tabular}




\section{Cureus}
al. [10], 2015 trial
patients who received rivaroxaban had a lower rate of ischemic stroke compared to patients who received warfarin (1.48 vs. 1.55 per 100 patient-years). Non-diabetic patients had similar results (1.71 vs. 1.80 per 100 patient-years).

\begin{tabular}{|lllll} 
Magnani et & Randomized & & & \\
al. [25], & controlled & 7,035 & 7,036 & 14,071 \\
2016 & trial & & &
\end{tabular}
Fordyce et Randomized
al. [14], 2016 tria trial
6,359
6,253
Lopes et al.
Randomized
[3], 2018 trial
Hohnloser et al. [24], 2018 controlled 374 trial

\section{4}
187
561
(1)
Hong et al. [13], 2017 Randomized controlled 95 trial

$\begin{array}{llll} & & & \\ \begin{array}{l}\text { Randomized } \\ \text { controlled }\end{array} & 95 & 88 & 183\end{array}$
88 $4,300 \quad 4,600$
Randomized
Zhu et al. [19], 2017 controlled 30 trial
They evaluated 5,926 participants with no history of $\mathrm{HF}$ and 6,355 patients with class I-II HF, and 1,801 patients with class III-IV HF. The efficacy and safety of edoxaban in patients with mild to severe HF were similar ( 1.54 for no HF vs. 1.52 for mild HF, and 1.83 per 100 patient-years for severe HF). The result was similar to a patient without HF.
Participants include 9,292 patients with normal renal function and 3,320 patients with renal failure (RF). As a result, patients with moderate RF (creatinine clearance of higher than $30 \mathrm{~mL} / \mathrm{min}$ ) do not need any dose adjustment for rivaroxaban $(15-20 \mathrm{mg}$ of rivaroxaban per day). In this study, patients with RF who received rivaroxaban had a slightly lower risk of ischemic stroke and systemic embolism compared with similar patients who received warfarin (1.54 vs.3.25 per 100 patient-years). There was not any difference in the chance of major bleeding between the two groups.
Apixaban was superior to vitamin $\mathrm{K}$ antagonists (warfarin) in the prevention of ischemic stroke. Also, patients who received apixaban with or without ASA have less possibility of ISTH major bleeding (31\% reduction).
Patients who underwent catheter ablation have about $0.5 \%$ to $3 \%$ risk of thromboembolic effects. In this study, 374 patients who were supposed to have catheter ablation received $60 \mathrm{mg}$ of edoxaban daily, and 187 patients were treated with warfarin (at least 21-28 days before the catheter ablation). The risk of an ischemic stroke for patients who received warfarin before and after the catheter ablation was less than $1 \%$ similar to the edoxaban group. The rate of major bleeding events was higher in patients who received warfarin $(6.9 \%)$ compared with $1.6 \%$ in the edoxaban group.
All patients in this study had at least one ischemic stroke before (confirmed by MRI). From 95 patients who were treated with rivaroxaban, 28 patients $(29.5 \%)$ had a recurrent ischemic stroke, and 30 patients $(31.6 \%)$ had an intracranial hemorrhage in four weeks. However, the number of patients in the warfarin group who experienced another ischemic stroke was 48 patients $(54.5 \%)$ and 31 patients $(35.6 \%)$ had an intracranial hemorrhage (in four weeks).
This study evaluated the metabolic benefits of rivaroxaban over warfarin in 60 patients who underwent a radiofrequency catheter ablation (RFCA). Metabolic indices like high-density lipoproteins (HDL), serum total proteins, globulin, and albumin were checked after RFCA. In 15 days following RFCA, the HDL level was 1.4 $\mathrm{mmol} / \mathrm{L}$ for the rivaroxaban group and $1.1 \mathrm{mmol} / \mathrm{L}$ for the warfarin group. Also, the amounts of serum total protein (75.8 vs. $66.8 \mathrm{~g} / \mathrm{L})$, albumin (45.4 vs. $40.5 \mathrm{~g} / \mathrm{L})$, and globulin (30.4 vs. $26.3 \mathrm{~g} / \mathrm{L}$ ) were higher in the rivaroxaban group. It sounds that due to the different drug-food interactions of warfarin, rivaroxaban has some metabolic benefits over warfarin.

\section{TABLE 3: Summary of the studies that compared the efficacy and safety of direct factor $\mathrm{Xa}$} inhibitors with warfarin.

AF, atrial fibrillation; ECG, electrocardiogram; HF, heart failure; ISTH, International Society of Thrombosis and Haemostasis; xaban, direct factor Xa inhibitor 
incidence of bleeding events in patients who received xabans or warfarin. We aimed to demonstrate that xabans are superior or have at least the same efficacy of warfarin with a slightly less intracranial hemorrhage and major bleeding events. As xabans do not need continuous blood monitoring and less drug interaction, they are superior to warfarin in the prevention of a primary and secondary ischemic stroke in patients with non-valvular AF. Considering patients' age, previous stroke, previous history of any major bleeding, CHA2DS2-VASc scores, and kidney and liver function, xabans have become the first choice of many physicians over warfarin for prevention of primary and secondary stroke in patients with non-valvular AF. Even though the risk of primary outcomes (ischemic stroke) and secondary outcome (any cause of death) increases by age, xabans are still superior to warfarin in the prevention of ischemic stroke events even in patients over 75 years of age. During our review, we found that like major bleedings, non-major bleedings were also more common in patients treated with warfarin.

There are still some challenging questions regarding the potential benefits of xabans over warfarin: Are they going to be approved for valvular AF? What are their other potential benefits over warfarin? Patients with valvular heart disease have more chances for $\mathrm{AF}$, but we found very few studies that evaluated the advantages and disadvantages of xabans vs. warfarin in patients who had significant valvular heart disease and AF. Most studies on xabans excluded patients with moderate to severe mitral stenosis. Due to the limitation of current studies on subjects with valvular AF, the efficacy and safety of xabans vs. warfarin for patients with valvular AF can be tested in future studies.

\section{Additional Information \\ Disclosures}

Conflicts of interest: In compliance with the ICMJE uniform disclosure form, all authors declare the following: Payment/services info: All authors have declared that no financial support was received from any organization for the submitted work. Financial relationships: All authors have declared that they have no financial relationships at present or within the previous three years with any organizations that might have an interest in the submitted work. Other relationships: All authors have declared that there are no other relationships or activities that could appear to have influenced the submitted work.

\section{References}

1. Granger $\mathrm{CB}$, Alexander JH, McMurray JJ, et al.: Apixaban versus warfarin in patients with atrial fibrillation . N Engl J Med. 2011, 365:981-992. 10.1056/NEJMoa1107039

2. Patel MR, Hellkamp AS, Lokhnygina Y, et al.: Outcomes of discontinuing rivaroxaban compared with warfarin in patients with nonvalvular atrial fibrillation: analysis from the ROCKET AF trial (Rivaroxaban Once-Daily, Oral, Direct Factor Xa Inhibition Compared With Vitamin K Antagonism for Prevention of Stroke and Embolism Trial in Atrial Fibrillation). J Am Coll Cardiol. 2013, 61:651-658. 10.1016/j.jacc.2012.09.057

3. Lopes RD, Vora AN, Liaw D, et al.: An open-Label, $2 \times 2$ factorial, randomized controlled trial to evaluate the safety of apixaban vs. vitamin $\mathrm{K}$ antagonist and aspirin vs. placebo in patients with atrial fibrillation and acute coronary syndrome and/or percutaneous coronary intervention: rationale and design of the AUGUSTUS trial. Am Heart J. 2018, 200:17-23. 10.1016/j.ahj.2018.03.001

4. Giugliano RP, Ruff CT, Braunwald E, et al.: Edoxaban versus warfarin in patients with atrial fibrillation . N Engl J Med. 2013, 369:2093-2104. 10.1056/NEJMoa1310907

5. Hum J, Shatzel JJ, Jou JH, Deloughery TG: The efficacy and safety of direct oral anticoagulants vs traditional anticoagulants in cirrhosis. Eur J Haematol. 2017, 98:393-397. 10.1111/ejh.12844

6. Osawa K, Nakanishi R, Win TT, et al.: Rationale and design of a randomized trial of apixaban vs warfarin to evaluate atherosclerotic calcification and vulnerable plaque progression. Clin Cardiol. 2017, 40:807-813. 10.1002/clc. 22746

7. Reynolds MR, Allison JS, Natale A, et al.: A prospective randomized trial of apixaban dosing during atrial fibrillation ablation: the AEIOU trial. JACC Clin Electrophysiol. 2018, 4:580-588. 10.1016/j.jacep.2017.11.005

8. Halvorsen S, Atar D, Yang H, et al.: Efficacy and safety of apixaban compared with warfarin according to age for stroke prevention in atrial fibrillation: observations from the ARISTOTLE trial. Eur Heart J. 2014, 35:1864-1872. 10.1093/eurheartj/ehu046

9. Bahit MC, Lopes RD, Wojdyla DM, et al.: Non-major bleeding with apixaban versus warfarin in patients with atrial fibrillation. Heart. 2017, 103:623-628. 10.1136/heartjnl-2016-309901

10. Bansilal S, Bloomgarden Z, Halperin JL, et al.: Efficacy and safety of rivaroxaban in patients with diabetes and nonvalvular atrial fibrillation: the Rivaroxaban Once-daily, Oral, Direct Factor Xa Inhibition Compared with Vitamin K Antagonism for Prevention of Stroke and Embolism Trial in Atrial Fibrillation (ROCKET AF Trial). Am Heart J. 2015, 170:675-682. 10.1016/j.ahj.2015.07.006

11. Halperin JL, Hankey GJ, Wojdyla DM, et al.: Efficacy and safety of rivaroxaban compared with warfarin among elderly patients with nonvalvular atrial fibrillation in the Rivaroxaban Once Daily, Oral, Direct Factor Xa Inhibition Compared With Vitamin K Antagonism for Prevention of Stroke and Embolism Trial in Atrial Fibrillation (ROCKET AF). Circulation. 2014, 130:138-146. 10.1161/CIRCULATIONAHA.113.005008

12. Balla SR, Cyr DD, Lokhnygina Y, et al.: Relation of risk of stroke in patients with atrial fibrillation to body mass index (from patients treated with rivaroxaban and warfarin in the rivaroxaban once daily oral direct factor Xa inhibition compared with vitamin $\mathrm{K}$ antagonism for prevention of stroke and embolism trial in atrial fibrillation trial). Am J Cardiol. 2017, 119:1989-1996. 10.1016/j.amjcard.2017.03.028

13. Hong KS, Kwon SU, Lee SH, et al.: Rivaroxaban vs warfarin sodium in the ultra-early period after atrial 
fibrillation-related mild ischemic stroke: a randomized clinical trial. JAMA Neurol. 2017, 74:1206-1215. 10.1001/jamaneurol.2017.2161

14. Fordyce CB, Hellkamp AS, Lokhnygina Y, et al.: On-treatment outcomes in patients with worsening renal function with rivaroxaban compared with warfarin: insights from ROCKET AF. Circulation. 2016, 134:37-47. 10.1161/CIRCULATIONAHA.116.021890

15. Sherwood MW, Nessel CC, Hellkamp AS, et al.: Gastrointestinal bleeding in patients with atrial fibrillation treated with rivaroxaban or warfarin: ROCKET AF trial. J Am Coll Cardiol. 2015, 66:2271-2281. 10.1016/j.jacc.2015.09.024

16. Breithardt G, Baumgartner H, Berkowitz SD, et al.: Clinical characteristics and outcomes with rivaroxaban vs. warfarin in patients with non-valvular atrial fibrillation but underlying native mitral and aortic valve disease participating in the ROCKET AF trial. Eur Heart J. 2014, 35:3377-3385. 10.1093/eurheartj/ehu305

17. Patel MR, Mahaffey KW, Garg J, et al.: Rivaroxaban versus warfarin in nonvalvular atrial fibrillation. N Engl J Med . 2011, 365:883-891. 10.1056/NEJMoa1009638

18. Piccini JP, Garg J, Patel MR, et al.: Management of major bleeding events in patients treated with rivaroxaban vs. warfarin: results from the ROCKET AF trial. Eur Heart J. 2014, 35:1873-1880. 10.1093/eurheartj/ehu083

19. Zhu J, Gao RJ, Liu Q, et al.: Metabolic benefits of rivaroxaban in non-valvular atrial fibrillation patients after radiofrequency catheter ablation. J Zhejiang Univ Sci B. 2017, 18:946-954. 10.1631/jzus.B1600492

20. Goodman SG, Wojdyla DM, Piccini JP, et al.: Factors associated with major bleeding events: insights from the ROCKET AF trial (rivaroxaban once-daily oral direct factor Xa inhibition compared with vitamin $\mathrm{K}$ antagonism for prevention of stroke and embolism trial in atrial fibrillation). J Am Coll Cardiol. 2014, 63:891-900. 10.1016/j.jacc.2013.11.013

21. Piccini JP, Hellkamp AS, Washam JB, et al.: Polypharmacy and the efficacy and safety of rivaroxaban versus warfarin in the prevention of stroke in patients with nonvalvular atrial fibrillation. Circulation. 2016, 133:352-360. 10.1161/CIRCULATIONAHA.115.018544

22. Sherwood MW, Douketis JD, Patel MR, et al.: Outcomes of temporary interruption of rivaroxaban compared with warfarin in patients with nonvalvular atrial fibrillation: results from the rivaroxaban once daily, oral, direct factor Xa inhibition compared with vitamin K antagonism for prevention of stroke and embolism trial in atrial fibrillation (ROCKET AF). Circulation. 2014, 129:1850-1859.

10.1161/CIRCULATIONAHA.113.005754

23. Hankey GJ, Stevens SR, Piccini JP, et al.: Intracranial hemorrhage among patients with atrial fibrillation anticoagulated with warfarin or rivaroxaban: The rivaroxaban once daily, oral, direct factor Xa inhibition compared with vitamin $\mathrm{K}$ antagonism for prevention of stroke and embolism trial in atrial fibrillation. Stroke. 2014, 45:1304-1312. 10.1161/STROKEAHA.113.004506

24. Hohnloser SH, Camm J, Cappato R, et al.: Uninterrupted administration of edoxaban vs vitamin K antagonists in patients undergoing atrial fibrillation catheter ablation: rationale and design of the ELIMINATE-AF study. Clin Cardiol. 2018, 41:440-449. 10.1002/clc.22918

25. Magnani G, Giugliano RP, Ruff CT, et al.: Efficacy and safety of edoxaban compared with warfarin in patients with atrial fibrillation and heart failure: insights from ENGAGE AF-TIMI 48. Eur J Heart Fail. 2016, 18:1153-1161. 10.1002/ejhf.595

26. De Caterina R, Renda G, Carnicelli AP, et al.: Valvular heart disease patients on edoxaban or warfarin in the ENGAGE AF-TIMI 48 trial. J Am Coll Cardiol. 2017, 69:1372-1382. 10.1016/j.jacc.2016.12.031

27. Corbalán R, Nicolau JC, López-Sendon J, et al.: Edoxaban versus warfarin in Latin American patients with atrial fibrillation: the ENGAGE AF-TIMI 48 trial. J Am Coll Cardiol. 2018, 72:1466-1475. 10.1016/j.jacc.2018.07.037

28. Okumura K, Lip GYH, Akao M, et al.: Edoxaban for the management of elderly Japanese patients with atrial fibrillation ineligible for standard oral anticoagulant therapies: Rationale and design of the ELDERCARE-AF study. Am Heart J. 2017, 194:99-106. 10.1016/j.ahj.2017.08.017

29. Lip GYH, Merino JL, Dan GA, et al.: Relation of stroke and bleeding risk profiles to efficacy and safety of edoxaban for cardioversion of atrial fibrillation (from the EdoxabaN Versus Warfarin in subjectS UndeRgoing cardiovErsion of Atrial Fibrillation [ENSURE-AF] study). Am J Cardiol. 2018, 121:193-198. 10.1016/j.amjcard.2017.10.008

30. Lip GYH, Halperin JL, Petersen P, Rodgers GM, Pall D, Renfurm RW: A phase II, double-blind, randomized, parallel group, dose-finding study of the safety and tolerability of darexaban compared with warfarin in patients with non-valvular atrial fibrillation: the oral factor Xa inhibitor for prophylaxis of stroke in atrial fibrillation study 2 (OPAL-2). J Thromb Haemost. 2015, 13:1405-1413. 10.1111/jth.13025

31. Franchi C, Antoniazzi S, Proietti M, Nobili A, Mannucci PM; SIM-AF Collaborators: Appropriateness of oral anticoagulant therapy prescription and its associated factors in hospitalized older people with atrial fibrillation. Br J Clin Pharmacol. 2018, 84:2010-2019. 10.1111/bcp.13631

32. Datar M, Crivera C, Rozjabek H, et al.: Comparison of real-world outcomes in patients with nonvalvular atrial fibrillation treated with direct oral anticoagulant agents or warfarin. Am J Health Syst Pharm. 2019, 76:275-285. 10.1093/ajhp/zxy032

33. Steinberg BA, Simon DN, Thomas L, et al.: Management of major bleeding in patients with atrial fibrillation treated with non-vitamin $\mathrm{K}$ antagonist oral anticoagulants compared with warfarin in clinical practice (from phase II of the Outcomes Registry for Better Informed Treatment of Atrial Fibrillation [ORBIT-AF II]). Am J Cardiol. 2017, 119:1590-1595. 10.1016/j.amjcard.2017.02.015

34. Steinberg BA, Shrader P, Thomas L, et al.: Factors associated with non-vitamin K antagonist oral anticoagulants for stroke prevention in patients with new-onset atrial fibrillation: Results from the Outcomes Registry for Better Informed Treatment of Atrial Fibrillation II (ORBIT-AF II). Am Heart J. 2017, 189:40-47. 10.1016/j.ahj.2017.03.024

35. Akao M, Chun YH, Esato M, et al.: Inappropriate use of oral anticoagulants for patients with atrial fibrillation. Circ J. 2014, 78:2166-2172. 10.1253/circj.cj-14-0344 